\title{
Female reproductive patterns in the millipede Polydesmus angustus (Diplopoda: Polydesmidae) and their significance for cohort-splitting
}

\author{
JEAN-FrANÇOIS DAVID \\ Centre d'Ecologie Fonctionnelle \& Evolutive, CNRS, 1919 route de Mende, F-34293 Montpellier cedex 5, France; \\ e-mail: jean-francois.david@cefe.cnrs.fr
}

Key words. Diplopoda, Polydesmus angustus, reproduction, life cycle, cohort-splitting, parsivoltinism

\begin{abstract}
First-stadium juveniles of Polydesmus angustus born each month from May to September were reared throughout their life cycle under controlled seasonal conditions. At maturity, the reproductive patterns of 62 females were studied individually. It was confirmed that females born from May to August have a 1-year life cycle and those born from late August onwards a 2-year life cycle (cohort-splitting). A third type of life cycle - interseasonal iteroparity - was observed in a few females born late in the season. On average, annual females started to reproduce when 11.4 months old and produced 3.6 broods per female over 1.8 months; the later they were born from May to August, the later they reproduced the following year. Biennial females started to reproduce when 19.9 months old and produced 3.8 broods per female over 2.2 months; all reproduced early in the breeding season. These results indicate that only annual females can produce an appreciable proportion of biennial offspring from late August onwards, which rules out direct genetic determination of life-cycle duration. The reproductive characteristics of $P$. angustus suggest a non-genetic mechanism that can drive cohort-splitting. Because individual females reproduce for about 2 months on average, this automatically results in cyclic variation in life-cycle duration (annual/biennial/annual) in the long-term progeny of any female.
\end{abstract}

\section{INTRODUCTION}

In many arthropod species, the duration of the life cycle varies among individuals of the same generation (Waldbauer, 1978; Tauber et al., 1986; Danks, 1994). The situation in which individuals reproduce after 1 year and others after 2 or more years within the same population is referred to as cohort-splitting (Sunderland et al., 1976) or parsivoltinism in insects (Torchio \& Tepedino, 1982). Willows (1987) argued that the term year-class splitting would be more appropriate, but the original term can be retained if a cohort is defined as the members of a population born in the same breeding season (Sunderland et al., 1976; Stearns, 1992). The biological mechanisms that lead to cohort-splitting vary among species, since individual variation in life-cycle duration may result from (1) distinct recruitment periods coupled with environmental influences during development, as in the woodlouse Philoscia muscorum (Grundy \& Sutton, 1989); (2) a genetic polymorphism, as suggested in the butterfly Maculinea rebeli (Thomas et al., 1998); (3) maternal effects, which can control offspring development not only at the egg stage but also later in the life cycle (Mousseau \& Dingle, 1991); and (4) a combination of these different mechanisms, as in the moth Zygaena trifolii (Wipking \& Mengelkoch, 1994).

In the millipede Polydesmus angustus Latzel, 1884, field studies suggested that individuals born in the same year within a population reproduced either after 1 or 2 years (David et al., 1993). This was confirmed in laboratory cultures kept under seasonal conditions, in which both types of life cycle were obtained (David et al., 1999). During the long breeding season, from May to early October, individuals born early were annual, whereas those born towards the end of the season were biennial. Two steps were identified in the extended life cycle: (1) biennial individuals of both sexes aestivated in the penultimate stadium (stadium VII) during the first breeding season after their birth and reached maturity in early autumn; (2) adult females emerging in autumn did not reproduce immediately; they overwintered a second time and reproduced in the second breeding season after birth (David et al., 1999). Further experiments have shown that the development of stadium VII is slowed by long days, whereas females enter reproductive diapause when exposed to short days (David et al., 2003). Therefore, individuals that do not reach stadium VII early enough in spring are channelled towards a biennial cycle by a two-stage photoperiodic response, as in certain insects (Butterfield et al., 2001). It is not known, however, whether this mechanism of cohort-splitting is only controlled by environmental factors during development, or whether genetic or maternal components are also involved.

The aim of the present study was to clarify the reproductive patterns of annual and biennial females of $P$. angustus. The first objective was to provide quantitative data on millipede reproduction, which are often incomplete due to the cryptic habits of the animals and the length of time required for rearing (Snider, 1981a; Hopkin \& Read, 1992). Another objective was to shed some light on the mechanism of cohort-splitting. Since an individual's life cycle seemingly depends on its month of birth, a better understanding of cohort-splitting could be achieved by determining the months in which annual and biennial females reproduce. This would make it possible 
to identify which females produce biennial offspring by the end of the breeding season. Genetic models for the determination of life-cycle duration could be considered if biennial offspring were primarily produced by biennial females.

Specifically, the aims of this study were (1) to confirm that the month of birth determines life-cycle duration in $P$. angustus, by rearing millipedes born to a larger number of parents than in previous studies; (2) to clarify the reproductive patterns of annual and biennial females by counting how many offspring they produce each month until they die; and (3) subject to confirmation of the first aim, to use the reproductive patterns to assess the expected proportions of the two life cycles in the progeny of annual and biennial females. For these purposes, millipedes born each month in the breeding season were monitored throughout their life cycle in a seasonal environment. Laboratory rearing was conducted under temperature and photoperiod conditions simulating those in the field, failing which cohorts might not split as they do under field conditions (Grundy \& Sutton, 1989).

\section{MATERIAL AND METHODS}

\section{Biological material}

The flat-backed millipede $P$. angustus is very common in north-western Europe (Kime, 1990). This saprophagous macroarthropod is particularly abundant in woodland, where it occurs in leaf litter or under dead bark. Its post-embryonic development invariably consists of eight stadia (= instars), the last of which is the adult (Enghoff et al., 1993). Individuals can be assigned to a stadium by counting the number of body rings and sexed from stadium IV onwards. Polydesmus females lay eggs in nests made of earthy faecal material, which are easy to find in cultures, and first stadium juveniles leave the nest soon after hatching (Snider, 1981b).

All millipedes used in this study originated from Brunoy, 20 $\mathrm{km}$ south-east of Paris, France. They were born to adults either collected from the field or reared for one generation under seasonal conditions. Juveniles born each month from May to September were taken from 18 broods produced by 16 mothers, which ensured a degree of genetic diversity within the samples. Broods produced in the same month were derived from at least three different mothers, except in May (two mothers). The life cycle of parents from the field was not known, but parents from the laboratory included both annual females $(n=9$, mated with annual males in at least two cases) and biennial females $(\mathrm{n}=3$, mated with biennial males in at least two cases).

\section{Laboratory rearing}

Although this study is based on data gathered over several years, all millipedes were reared under the same controlled conditions. Within a few days of hatching, first stadium juveniles were transferred with a brush to lidded, transparent plastic boxes (400 ml), containing about $1 \mathrm{~cm}$ of sieved soil (particle size $<2$ $\mathrm{mm}$ ) and moist leaf litter. The boxes were placed in incubators fitted with a glass door. Temperature followed the mean monthly temperatures of the region of origin (Fig. 1), with a daily thermoperiod ( $12 \mathrm{~h}$ cryophase : $12 \mathrm{~h}$ thermophase) of $4^{\circ} \mathrm{C}$ amplitude, or $2{ }^{\circ} \mathrm{C}$ in the three coldest months. The boxes were exposed to the natural daylight of Montpellier, southern France (Fig. 1), which gives life cycles similar to those obtained at the Brunoy photoperiod (David et al., 1999). The millipedes were fed continually with a mixture of chestnut, hazel, hornbeam and

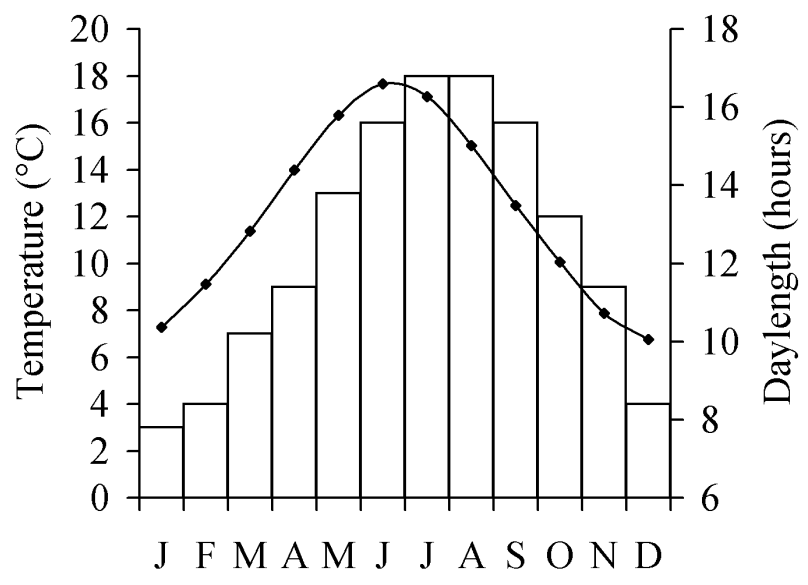

Fig. 1. The average seasonal environment conditions of temperature (bar graph) and photoperiod (line graph) in which the millipedes were reared in the laboratory.

oak leaf litter rinsed in distilled water. In addition, they received a pinch of dry yeast (Saccharomyces cerevisiae) every month, which results in adult live weights and fertility close to those recorded in the field (David \& Celerier, 1997).

Juveniles from each brood were reared in groups of about twenty individuals during the earlier stadia. At stadium IV, survivors were sexed and distributed into several boxes to reduce population density. Randomly chosen females were subsequently isolated in new boxes to be monitored individually. They were mated when adult (stadium VIII) and their reproductive activity was recorded until they died. Every time a nest was found, the female was transferred to a new box to avoid mixtures of broods. Once eggs hatched, offspring were collected with Dumont tweezers and counted. For each female, the number of broods produced, the dates of hatching, and the number of offspring per brood (fertility) were recorded.

The birthday of an individual was the day on which it was first observed in stadium I. As the boxes were examined at least twice a week, the possible error in dating the birthday and other events in the life cycle (emergence, reproduction) was between 0 and 4 days. Data were converted into months on the basis of 30.4 days per month.

\section{Statistical analysis}

All tests were based on Sokal \& Rohlf (1995). The effects of month of birth on reproductive characteristics (age at first reproduction, duration of the breeding period, number of broods produced and lifetime fertility) were tested using one-way ANOVA. Before each analysis the equality of sample variances was tested using the $F_{\max }$-test and, in one case, data were powertransformed to make the variances uniform. A posteriori comparisons were made using the Tukey-Kramer procedure. The proportions of biennial offspring in females' progeny were compared using the $G$-test of independence with William's correction.

\section{RESULTS}

\section{Annual and biennial females}

The life cycle of females changed with the month of birth (Table 1). All females born from May to July, and most of those born in August, overwintered in a stadium $\geq \mathrm{V}$. They reached the adult stage before 4 July the following year, without aestivating in stadium VII, and reproduced in the first breeding season after birth. This is 
TABle 1. Frequencies of three types of life cycles in Polydesmus angustus, recorded for females born in different months and reared in the same seasonal environment.

\begin{tabular}{lcccc}
\hline \multirow{2}{*}{ Month of birth } & \multirow{2}{*}{$\begin{array}{c}\text { Number } \\
\text { of females }\end{array}$} & \multicolumn{3}{c}{ Type of life cycle } \\
\cline { 3 - 5 } & 7 & Annual & Biennial & Iteroparous \\
\hline May & 13 & 13 & - & - \\
June & 11 & 11 & - & - \\
July & 10 & 10 & - & - \\
August, fortnight 1 & 8 & 5 & 2 & 1 \\
August, fortnight 2 & 13 & - & 11 & 2 \\
September & 62 & 46 & 13 & 3 \\
Total & & &
\end{tabular}

the annual type of life cycle (46 out of 62 ). Typically, these females did not survive to the following breeding season. Only two survived to the start of the second season but did not reproduce.

In contrast, females that were born from 28 August onwards first overwintered in stadia III-IV and reached stadium VII by the end of the following spring. Most of these females aestivated in stadium VII, reached the adult stage after 29 September, overwintered a second time and started to reproduce in the second breeding season after birth. This is the biennial type of life cycle (13 out of 62).

Three late-born females had a third type of life cycle. Although they reached stadium VII at the same time as biennial females, they did not aestivate in that stadium. They became adults in late July and started to reproduce before the end of the first breeding season. These females overwintered a second time and resumed reproduction in the second breeding season after birth. This type of life cycle is referred to as interseasonal iteroparity.

\section{Reproductive patterns of females}

Reproductive characteristics of females are detailed in Table 2. On average, annual females started to reproduce at 11.4 months of age; their breeding period, i.e. the time between the hatch of the first and last broods, lasted 1.8 months, during which they produced 3.6 broods; their mean lifetime fertility was 762 offspring per female. These characteristics varied little with the month of birth of annual females, except for a marginally significant difference between the age at first reproduction of those born in May and July (ANOVA, $\mathrm{P}=0.04$ ). In biennial females, age at first reproduction (19.9 months on average) was significantly greater than in annual females (ANOVA, $\mathrm{P}<0.001$ ). The duration of the breeding period, number of broods per female, and lifetime fertility were slightly, but not significantly, higher than for annual females. The three iteroparous females had a comparatively low fertility, especially in their second breeding season, during which they produced fewer offspring than strictly biennial females (ANOVA, $\mathrm{P}<0.01$ ).

Reproductive patterns, determined for all females born in the same months, are shown in Fig. 2. Clearly, there was a shift in the breeding periods in relation to the month of birth. Annual females born in May started to reproduce in May with a peak in May; those born in June
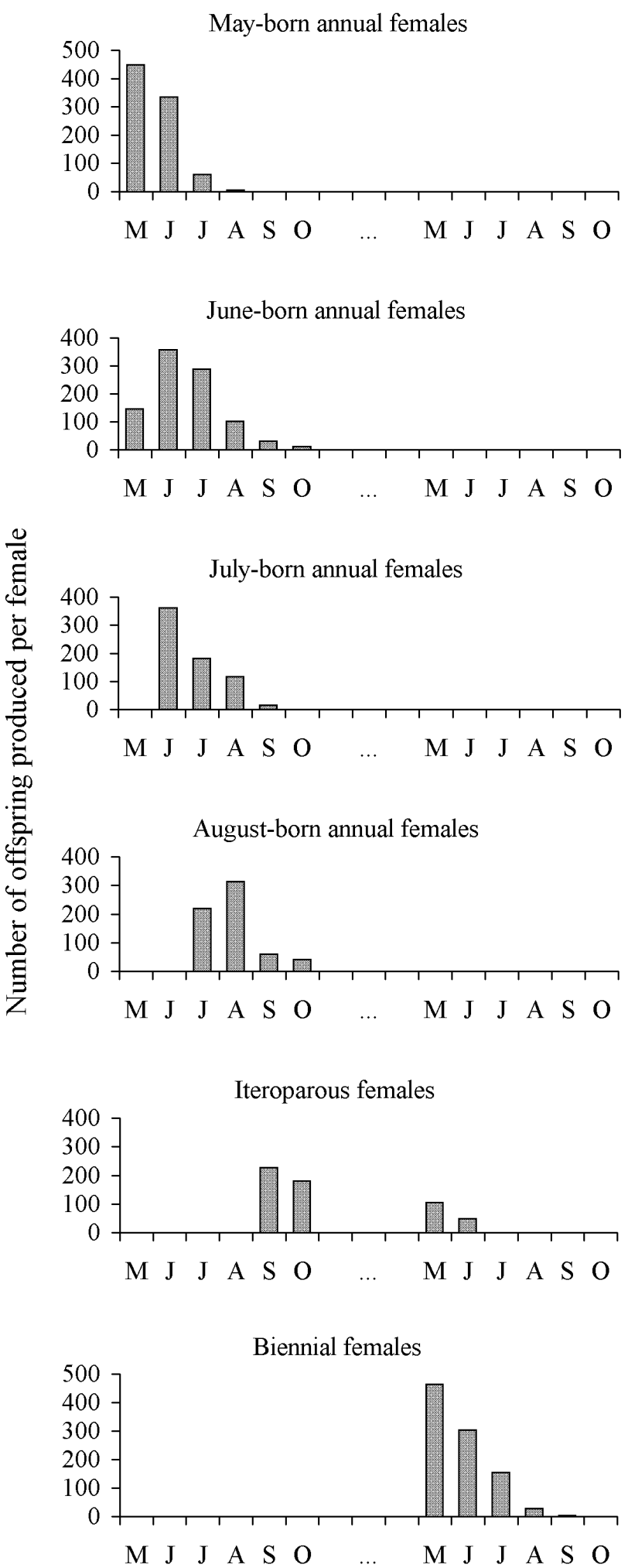

Fig. 2. The reproductive patterns of female Polydesmus angustus that were born from May to September and reared throughout their life cycle in the same seasonal environment.

started to reproduce in May with a peak in June; those born in July started to reproduce in June with a peak in June; and those born in August started to reproduce in July with a peak in August (Fig. 2). The three iteroparous females (born in late August-September) reproduced 
TABLE 2. Reproductive characteristics of Polydesmus angustus females, in relation to their month of birth and type of life cycle: age at first reproduction (in months), duration of the breeding period (in months), number of broods produced, and lifetime fertility (means $\pm \mathrm{SE}$ ).

\begin{tabular}{|c|c|c|c|c|c|c|c|c|}
\hline \multirow{2}{*}{$\begin{array}{l}\text { Month of birth and } \\
\text { type of life cycle }\end{array}$} & \multirow{2}{*}{$\begin{array}{l}\text { Number } \\
\text { of females }\end{array}$} & \multirow{2}{*}{$\begin{array}{l}\text { Age at first } \\
\text { reproduction }\end{array}$} & \multicolumn{2}{|c|}{$\begin{array}{c}\text { Duration of } \\
\text { the breeding period }\end{array}$} & \multicolumn{2}{|c|}{$\begin{array}{c}\text { Number of } \\
\text { broods per female }\end{array}$} & \multicolumn{2}{|c|}{$\begin{array}{c}\text { Number of } \\
\text { offspring per female }\end{array}$} \\
\hline & & & 1 st year & 2nd year & 1st year & 2nd year & 1st year & 2nd year \\
\hline May, annual & 7 & $11.8 \pm 0.2$ & $1.3 \pm 0.4$ & - & $3.1 \pm 0.5$ & - & $849 \pm 115$ & - \\
\hline June, annual & 13 & $11.4 \pm 0.2$ & $2.3 \pm 0.4$ & - & $4.2 \pm 0.6$ & - & $936 \pm 114$ & - \\
\hline July, annual & 11 & $11.1 \pm 0.2$ & $1.6 \pm 0.4$ & - & $3.2 \pm 0.7$ & - & $674 \pm 134$ & - \\
\hline August, annual & 15 & $11.3 \pm 0.1$ & $2.0 \pm 0.1$ & - & $3.7 \pm 0.3$ & - & $634 \pm 62$ & - \\
\hline $\begin{array}{l}\text { late August \& } \\
\text { September, biennial }\end{array}$ & 13 & $19.9 \pm 0.1$ & - & $2.2 \pm 0.2$ & - & $3.8 \pm 0.5$ & - & $956 \pm 114$ \\
\hline $\begin{array}{l}\text { late August \& } \\
\text { September, iteroparous }\end{array}$ & 3 & $11.9 \pm 0.2$ & $1.1 \pm 0.2$ & $0.9 \pm 0.1$ & $2.0 \pm 0.0$ & $1.3 \pm 0.7$ & $408 \pm 43$ & $153 \pm 80$ \\
\hline
\end{tabular}

even later in their first breeding season, starting in September; but in their second breeding season they started to reproduce in May with a peak in May. Likewise, biennial females (all born in late August-September) started to reproduce in May with a peak in May in the second breeding season after their birth (Fig. 2).

\section{Life cycles of the progeny}

By combining data on the female reproductive patterns (Fig. 2) with the relative frequencies of the different types of life cycles (Table 1), it was possible to assess the expected proportions of biennial offspring in the progeny of females whose birthday was known. From Table 1, biennial offspring were assumed to represent $25 \%$ of the offspring hatching in late August and $85 \%$ of those hatching in September. Under the environmental conditions used in this study, annual females born in May, which reproduced early in the season, were unlikely to produce any biennial offspring; annual females born in June and July reproduced a little later and were expected to produce 5 and $4 \%$ biennial offspring, respectively; annual females born in August were expected to produce significantly more biennial offspring than the previous groups $(20 \%$; $G$-test, $\mathrm{P}<0.001)$. On the other hand, biennial females, which reproduced early in the second breeding season after their birth, were unlikely to produce a significant proportion of biennial offspring (only $0.3 \%$ ).

\section{DISCUSSION}

This study has confirmed that the life cycle of $P$. angustus varies among individuals reared in the same seasonal environment and strongly depends on the month of birth. As in David et al. (1999), all females that were born in the first part of the season (May-August) were annual, whereas those that were born by the end of the season (late August and later) were biennial. This pattern was unlikely to have been obtained by chance as the sample of females came from 18 different broods. It can therefore be concluded that, in this species, the month of birth has a decisive influence on the life cycle of individuals that develop under seasonal conditions.
A third type of life cycle was observed in a few females, which laid eggs in two successive breeding seasons (i.e., interseasonal iteroparity - Hopkin \& Read, 1992). The iteroparous females were born in the same period and began developing at the same rate as biennial females, but did not aestivate in stadium VII. It is uncertain whether this type of life cycle, previously unrecorded in the Polydesmida (Snider, 1981a; Hopkin \& Read, 1992), can influence the dynamics of field populations. It is unknown whether the lack of aestivation results from genetic differences, in which case it would be heritable, or from environmental influences, both of which can affect the occurrence and duration of diapause in arthropods (Tauber et al., 1986; Danks, 2002). Environmental conditions that induce aestivation in $P$. angustus are not yet fully elucidated (David et al., 2003) and may have been sub-optimal in our laboratory cultures. Taking this into account and the low frequency of iteroparous females $(<5 \%)$, they are provisionally ignored in the following discussion.

The reproductive pattern of biennial females, which is described here thoroughly for the first time, indicates that they reproduce primarily early in the season. Therefore, nearly all their offspring $(>99 \%)$ are destined to be annual. In contrast, the reproductive patterns of annual females indicate that some of these can reproduce up to the end of the season. Therefore, it is primarily annual females that produce biennial offspring. This conclusion is supported by comparing the life cycles of females with those of their mothers, where possible. The thirteen females that were biennial in this study all had annual mothers (fertilized by annual fathers in at least two cases). On the other hand, the ten females that were known to have biennial mothers (and also biennial fathers in eight cases) were all annual, in accordance with their month of birth. These observations rule out direct genetic determination of life-cycle duration. Under the constraint that all annual females are born early and all biennial ones late in the season, genetic models of inheritance, whether simple mendelian, polygenic, or non-mendelian (Snustad \& Simmons, 2006), would require that biennial females repro- 
duce late in the season. Mendelian and polygenic models would also require that biennial males reproduce late in the season, with a reduced level of intermating between annual and biennial millipedes. This is most unlikely for species in which all adults are reproductively active for weeks or months (Wise, 1987; Schultheis et al., 2002).

A close examination of the reproductive biology of $P$. angustus provides an alternative, non-genetic explanation for the production of biennial offspring. The results suggest that, over a number of generations, any female can potentially produce progeny with both annual and biennial life cycles. This possibility results from the duration of the breeding period of individual females, which lasts about 2 months on average. Consider an annual female born in May; it is likely to reproduce not only in May the following year, but also in June; its offspring born in June are likely to reproduce not only in June the following year, but also in July. Each year there is a shift in the breeding period of a proportion of the progeny, which can lead in a few generations to an appreciable proportion of late-hatching individuals (from late August to October). These millipedes will pass through two periods of dormancy and have a 2-year life cycle. However, their reproduction will be synchronized early in the season, so that they will produce a high proportion of annual individuals born in May. Therefore, while the majority of the population is annual, a part of each female's progeny is automatically involved in a cycle in life-cycle duration (annual/biennial/annual).

The proportion of biennial individuals is much lower in $P$. angustus than in other arthropods that show cohortsplitting (Torchio \& Tepedino, 1982; Thomas et al., 1998; Menu \& Desouhant, 2002). In this millipede, the proportion of long cycles probably depends on the number of generations required for completing the annual/biennial/annual cycle. The number of generations required first varies with the duration of the breeding period of individual females. In this study, breeding periods longer than 3 months (ten females) or even 4 months (two females) were observed, thus 2-year cycles may appear very quickly in the progeny. The number of generations required for completing the annual/biennial/annual cycle is also likely to vary with all factors that influence the rate of development. For example, elevated temperatures result in a more rapid development and an earlier breeding season in $P$. angustus (David \& Gillon, 2009), which should delay, or even prevent the appearance of 2-year cycles. Conversely, environmental conditions that delay the breeding season should accelerate the appearance of 2-year cycles in the progeny. Genetic differences between individuals affecting their development rate may also be important in this respect (Wipking \& Mengelkoch, 1994).

In conclusion, this study has shown that, in P. angustus, biennial offspring are produced late in the season, almost exclusively by annual females. This precludes the possibility of a genetic polymorphism for life-cycle duration. However, it remains to be determined whether cohortsplitting results only from environmental influences during development, as in the woodlouse Philoscia muscorum (Grundy \& Sutton, 1989), or whether a maternal effect, e.g. an effect mediated by maternal age, influences the development of offspring born late in the season (Mousseau \& Dingle, 1991; Fox \& Czesak, 2000).

ACKNOWLEDGEMENTS. I am very grateful to all people who helped with cultures, with special thanks to M. Castex, D. Degueldre and V. Sarda.

\section{REFERENCES}

Butterfield J., Whittaker J.B. \& Fielding C.A. 2001: Control of the flexible annual-biennial life cycle of the heather psyllid Strophingia ericae. Physiol. Entomol. 26: 266-274.

DANKS H.V. 1994: Diversity and integration of life-cycle controls in insects. In Danks H.V. (ed.): Insect Life-Cycle Polymorphism. Kluwer, Dordrecht, pp. 5-40.

DANKS H.V. 2002: The range of insect dormancy responses. Eur. J. Entomol. 99: 127-142.

DAVID J.F. \& Celerier M.L. 1997: Effects of yeast on the growth and reproduction of the saprophagous millipede Polydesmus angustus (Diplopoda, Polydesmidae). Biol. Fertil. Soils 24: 66-69.

David J.F. \& Gillon D. 2009: Combined effects of elevated temperatures and reduced leaf litter quality on the life-history parameters of a saprophagous macroarthropod. Global Change Biol. 15: 156-165.

David J.F, Couret T. \& Celerier M.L. 1993: The life cycle of the millipede Polydesmus angustus: another case of cohortsplitting. Eur. J. Soil Biol. 29: 117-125.

David J.F., Celerier M.L. \& Geoffroy J.J. 1999: Periods of dormancy and cohort-splitting in the millipede Polydesmus angustus (Diplopoda, Polydesmidae). Eur. J. Entomol. 96: 111-116.

David J.F., Geofrroy J.J. \& Celerier M.L. 2003: First evidence for photoperiodic regulation of the life cycle in a millipede species, Polydesmus angustus (Diplopoda, Polydesmidae). $J$. Zool. (Lond.) 260: 111-116.

Enghoff H., Dohle W. \& Blower J.G. 1993: Anamorphosis in millipedes (Diplopoda) - the present state of knowledge with some developmental and phylogenetic considerations. Zool. J. Linn. Soc. 109: 103-234.

Fox C.W. \& CZESAK M.E. 2000: Evolutionary ecology of progeny size in arthropods. Annu. Rev. Entomol. 45: 341-369.

Grundy A.J. \& Sutton S.L. 1989: Year class splitting in the woodlouse Philoscia muscorum explained through studies of growth and survivorship. Holarct. Ecol. 12: 112-119.

Hopkin S.P. \& READ H.J. 1992: The Biology of Millipedes. Oxford University Press, Oxford, $233 \mathrm{pp}$.

KIME R.D. 1990: A Provisional Atlas of European Myriapods Part 1. European Invertebrate Survey, Luxembourg, 109 pp.

Menu F. \& Desouhant E. 2002: Bet-hedging for variability in life cycle duration: bigger and later-emerging chestnut weevils have increased probability of a prolonged diapause. Oecologia 132: 167-174.

Mousseau T.A. \& Dingle H. 1991: Maternal effects in insect life histories. Annu. Rev. Entomol. 36: 511-534.

Schultheis A.S., Hendricks A.C. \& Weigt L.A. 2002: Genetic evidence for "leaky" cohorts in the semivoltine stonefly Peltoperla tarteri (Plecoptera: Peltoperlidae). Freshwater Biol. 47: 367-376.

SNIDER R.M. 1981a: The reproductive biology of Polydesmus inconstans (Diplopoda: Polydesmidae) at constant temperatures. Pedobiologia 22: 354-365. 
SNIDER R.M. 1981b: Growth and survival of Polydesmus inconstans (Diplopoda: Polydesmidae) at constant temperatures. Pedobiologia 22: 345-353.

Snustad D.P. \& Simmons M.J. 2006: Principles of Genetics. 4th ed. John Wiley \& Sons, $866 \mathrm{pp}$

Sokal R.R. \& Rohlf F.J. 1995: Biometry. 3rd ed. Freeman, New York, 887 pp.

Stearns S.C. 1992: The Evolution of Life Histories. Oxford University Press, Oxford, $249 \mathrm{pp}$.

Sunderland K.D., Hassall M. \& Sutton S.L. 1976: The population dynamics of Philoscia muscorum (Crustacea, Oniscoidea) in a dune grassland ecosystem. J. Anim. Ecol. 45 487-506.

Tauber M.J., Tauber C.A. \& Masaki S. 1986: Seasonal Adaptations of Insects. Oxford University Press, New York, 411 pp.

Thomas J.A., Elmes G.W. \& Wardlaw J.C. 1998: Polymorphic growth in larvae of the butterfly Maculinea rebeli, a social parasite of Myrmica ant colonies. Proc. R. Soc. Lond. (B) 265: 1895-1901.
Torchio P.F. \& Tepedino V.J. 1982: Parsivoltinism in three species of Osmia bees. Psyche 89: 221-238.

Waldbauer G.P. 1978: Phenological adaptation and the polymodal emergence patterns of insects. In Dingle H. (ed.): Evolution of Insect Migration and Diapause. Springer, New York, pp. 127-144.

WILLows R.I. 1987: Population dynamics and life history of two contrasting populations of Ligia oceanica (Crustacea: Oniscidea) in the rocky supralittoral. J. Anim. Ecol. 56: 315-330.

WiPKING W. \& MengelKoch C. 1994: Control of alternate-year flight activities in high-alpine Ringlet butterflies (Erebia, Satyridae) and Burnet moths (Zygaena, Zygaenidae) from temperate environments. In Danks H.V. (ed.): Insect LifeCycle Polymorphism. Kluwer, Dordrecht, pp. 313-347.

WISE D.H. 1987: Rearing studies with a spider exhibiting a variable phenology: no evidence of substantial genetic variation. Bull. Br. Arachnol. Soc. 7: 107-110.

Received January 19, 2009; revised and accepted February 17, 2009 